\title{
Pesquisa acadêmica como material didático na educação básica: o caso do relatório Diagnóstico geoambiental da APA da bacia hidrográfica do Rio Machado-MG
}

\author{
Academic research as didactic material in basic education: the report of \\ Geo-environmental diagnostic of hydrographical basin APE of Machado River-MG
}

\author{
Sandra de Castro de Azevedo \\ Doutora em Geografia \\ Docente da Universidade Federal de Alfenas-MG, Brasil \\ sandrinhacp@yahoo.com.br
}

\begin{abstract}
Resumo
A proximidade entre a universidade e a educação básica é essencial para o avanço na pesquisa em educação e em ensino. São dois espaços diferentes, com funções diferentes, mas que estão interligados. É comum ouvirmos que o que aprendemos na universidade é muito diferente do que estudamos na educação básica, no caso da geografia isso não se confirma, os conteúdos são os mesmos, mas a abordagem é diferente por que o objetivo fim é diferente, na universidade se formam geógrafos, na escola se forma para a vida. Este artigo visa analisar como um produto de pesquisa acadêmica pode ser inserido nas aulas de geografia da educação básica. A partir do relatório do Diagnóstico geoambiental da APA da bacia hidrográfica do Rio Machado-MG, elaboraram-se sequências didáticas com ênfase na linguagem cartográfica para desenvolver o raciocínio geográfico dos alunos, valorizando a contextualização de conteúdo. A proposta deste artigo é ressaltar que as pesquisas acadêmicas podem ser utilizadas diretamente em sala de aula, mas para isso é necessário um processo de divulgação, de acesso a esse material e de projeto de formação continuada para os professores da educação básica para que eles possam acompanhar a evolução da ciência geográfica.
\end{abstract}

Palavras-chave: Ensino de geografia, Contextualização, Linguagem Cartográfica.

\begin{abstract}
The proximity of university and basic education is essential for progress in teaching and education researches. Are two different spaces, with different functions, but they are interconnected. It is common to hear that what we learn in the university is very different of what we study on basic education, in Geography case this can't be confirmed, the content is absolutely the same, but approach is different because de end goal is different, in the university geographers are graduated, in the schools they are prepared for life. This article is aimed to analyses how an academic research product can be inserted on geography classes in basic education. From the diagnostic geo-environmental report of hydrographical basin APE of Machado River-MG sequences teaching are elaborated with an emphasis on cartographical language to develop the students geographical reasoning adding value to contextualization of content, the purpose of this article is emphasize that academic research can be direct applicate in classroom, but for this is necessary a process to diffusion and facility the access of this material and a Project of continuing education to basic education teachers so they can be aware about geographical Science evolution.
\end{abstract}

Keywords: School geography, contextualization, cartographical language. 


\section{INTRODUÇÃO}

A geografia escolar e o ensino de geografia são objetos de estudos de várias pesquisas que buscam fortalecer a geografia na educação básica, realizando assim avanços em metodologia de ensino, em proposta de uso de linguagens diversas, na formação inicial e continuada de professores. Este artigo é resultado de um trabalho de elaboração de material didático a partir de um relatório de Diagnóstico geoambiental da APA da bacia hidrográfica do Rio Machado-MG, o qual possibilitou a reflexão sobre o uso dos materiais resultantes de pesquisa na educação e consequentemente da relação universidade e educação básica, pensando em estratégias que permitam que os resultados de pesquisas científicas cheguem até os professores de geografia.

Para conduzir as atividades didáticas desenvolvidas optou-se por ter como base a linguagem cartográfica, pois o relatório do Diagnóstico possui um excelente e diversificado material cartográfico e também porque muitas pesquisas comprovam que a cartografia escolar ainda é um desafio para os professores da educação básica, seja por falta de material para trabalhar ou por falhas na formação inicial e defasagem da oferta da formação continuada.

A partir do relatório final do diagnóstico foram elaboradas cinco sequências didáticas considerando como princípios: partir da linguagem cartográfica; enfatizar a relação sociedade e natureza; e buscar a contextualização sempre relacionando o local com o global. As sequências didáticas elaboradas foram: I. Trabalhar Escala Geográfica, Limites e Bacias Hidrográficas, II. Trabalhar Geomorfologia, Geologia e Uso e Ocupação do Solo, III. Trabalhar Relação Sociedade e Natureza, IV. Trabalhar as Questões Populacionais da APA e V. Trabalhar com Dados Climáticos e Ocupação Humana.

Para ressaltar como os projetos de pesquisas e seus resultados podem ser utilizados na educação básica, neste artigo será analisada a sequência didática I. Trabalhar Escala Geográfica, Limites e Bacias Hidrográficas, partindo de uma discussão sobre material didático, contextualização no ensino de geografia e cartografia escolar.

\section{A GEOGRAFIA ESCOLAR E A PESQUISA ACADÊMICA COMO MATERIAL DIDÁTICO: POSSIBILIDADES DE CONTEXTUALIZAÇÕES}

Existe uma linha de pesquisa na educação que defende a contextualização do conteúdo escolar à realidade do aluno. Muitos pesquisadores defendem que o conteúdo trabalhado na escola na maioria das vezes não é útil para o aluno, não leva o aluno a compreender sua realidade. 
Os professores de Geografia relatam que estão frequentemente enfrentando dificuldade em "atrair" seus alunos nas aulas, pois a maioria não se interessa pelos conteúdos que essa disciplina trabalha. No entanto, se a Geografia contempla a diversidade da experiência dos homens na produção do espaço, as questões espaciais estão sempre presentes no cotidiano de todos eles, sejam as de dimensões globais ou locais. É o caso de se questionar, então, por que os alunos não mostram interesse especial pelos conteúdos da disciplina, limitando-se, na maior parte das vezes, ao cumprimento formal das obrigações escolares (CAVALCANTI, 2010, p. 3).

No ensino de geografia existe um forte movimento iniciado pela geografia crítica de superar o ensino de geografia sem sentido, contudo a geografia tradicional ainda é muito presente na geografia escolar.

Se a tarefa do ensino é tornar os conteúdos veiculados objetos de conhecimento para o aluno e se a construção do conhecimento pressupõe curiosidade pelo saber, esse é um obstáculo que precisa efetivamente ser superado. Para despertar o interesse cognitivo dos alunos, o professor deve atuar na mediação didática, o que implica investir no processo de reflexão sobre a contribuição da Geografia na vida cotidiana, sem perder de vista sua importância para uma análise crítica da realidade social e natural mais ampla. Nesse sentido, o papel diretivo do professor na condução do ensino está relacionado às suas decisões sobre o que ensinar, o que é prioritário ensinar em Geografia, sobre as bases fundamentais do conhecimento geográfico a ser aprendido pelas crianças e jovens, reconhecendo esses alunos como sujeitos, que têm uma história e uma cognição a serem consideradas (CAVALCANTI, 2010, p. 3).

Duas hipóteses podem ser levantadas sobre esse processo, uma que está relacionada à formação inicial do professor de geografia, que muitas vezes consegue compreender o conteúdo específico de geografia, mas que tem dificuldade de transformar esse conteúdo para o formato escolar.

A consciência de que conhecer bem a matéria de ensino é importante, mas não é suficiente para a prática docentes já é parte dos pressupostos da formação inicial de professores, fundamentados em diferentes autores (como, por exemplos, Shulman, 2005; Gauthier, 1999; Cavalcanti, 2012). Essa consciência leva a que as disciplinas e atividades curriculares busquem articulação com a dimensão pedagógica da formação. Porém, na prática, a aprendizagem dos conteúdos geográficos articulados com suas finalidades educativas e suas possibilidades práticas de ensiná-los ainda é um grande desafio (CAVALCANTI, 2017, p. 102).

No entanto é importante ressaltar que existem pesquisadores da educação e do ensino de geografia que avançam nas pesquisas que buscam entender melhor o processo e elaborar metodologias e estratégias que superem esse obstáculo. Cavalcanti indica um caminho possível:

Para enfrentar esse desafio de trabalhar diferentes dimensões dos conteúdos, tenho indicado como eixo transversal articulador da formação inicial dos professores de geografia a problematização da Geografia Escolar (Cavalcanti, idem ibdem). Ou seja, entende-se que colocar a Geografia escolar como questão central e transversal para as reflexões, discussões, argumentações em todas as atividades de sala de aula ou fora dela, partindo, portanto, dos problemas que os alunos-futuros professores já percebem no desenvolvimento do pensamento geográfico e pedagógico orientador efetivo de sua prática profissional. Nesse mesmo encaminhamento da problematização, é possível trazer 
a tona os conhecimentos e crenças já adquiridos por esses sujeitos em formação, em sua história de vida e de escola, no sentido de colocar em questão seus saberes, para reafirmálos ou para negá-los, para superá-los. Esse pressuposto da formação tem como fundamento a necessidade de articulação e interdependência entre teoria e prática, entre ensino e pesquisa (Cavalcanti, op. cit) (CAVALCANTI, 2017, p. 103).

A outra hipótese está relacionada ao material didático, grande parte das escolas públicas utilizam livro didático, que é um instrumento importante na abordagem dos conteúdos, mas infelizmente muitas vezes o livro acaba sendo entendido pelo professor como o currículo.

Não há, portanto, agrupamentos naturais de conteúdos em saberes específicos ou em disciplinas escolares, ao contrário do que supõe a ilusão epistemológica. Pelo contrário, a constituição das disciplinas escolares foi um processo de conflitos, negociações e acomodações, que resulta naquilo que Chervel (1990) denomina vulgata:

Em cada época, o ensino dispensado pelos professores é, grosso modo, idêntico, para a mesma disciplina e para o mesmo nível. Todos os manuais ou quase todos dizem então a mesma coisa, ou quase isso. Os conceitos ensinados, a terminologia adotada, a coleção de rubricas e capítulos, a organização do corpus de conhecimentos, mesmo os exemplos utilizados ou os tipos de exercícios praticados são idênticos, com variações aproximadas. São apenas essas variações, aliás, que podem justificar a publicação de novos manuais e; de qualquer modo, não apresentam mais do que desvios mínimos: o problema do plágio é uma das constantes da edição escolar (MUNAKATA, 2016, p. 125).

É importante nesta análise inserir na discussão o Programa Nacional do Livro Didático (PNLD). Esse programa apresenta suas contradições, é um programa considerado relevante para a educação, pois muitos alunos filhos da classe trabalhadora não teriam condições de adquirir livros para auxiliar nos estudos, no entanto se torna um instrumento de reprodução ideológica.

Os livros didáticos foram utilizados em diferentes momentos da história do Brasil como instrumentos de reprodução ideológica das classes dominantes. Transmitiam valores ligados a esses grupos, constituindo uma mercadoria bastante lucrativa e que ainda hoje representa os interesses de determinados segmentos da sociedade. Atualmente, apesar de serem escolhidos pelos professores de maneira democrática, muitas vezes não contemplam a realidade social das diversas escolas existentes nesse Brasil continental. Além disso, para muitos alunos, representam a única referência para a introdução à chamada sociedade letrada, afirmando-se como um instrumento educacional complexo e ambíguo (ZACHEU; CASTRO, 2015, p. 2).

A proposta do governo de custear o material didático e torná-lo acessível na escola é entendida como algo positivo. Ainda mais porque ocorre a avaliação desses materiais seguindo uma série de critérios, o que evita que a escola receba livros com informações falsas ou erradas. De acordo com Vitiello (2018, p. 67):

A primeira avaliação para o PNLD voltado aos anos finais do Ensino Fundamental- no qual a Geografia é um componente curricular obrigatório- ocorreu em 1999. (...). Em 1999, a avaliação ocorreu de forma centralizada, cabendo à Secretaria do Ensino Fundamental (SEF), vinculada ao Ministério da Educação (MEC), convidar docentes de universidades e do ensino fundamental para realizar a avaliação das obras. 
A avaliação do livro didático atualmente deveria envolver professores universitários que pesquisam sobre a área e professores da educação básica, de forma coletiva, pois assim os livros teriam mais qualidade e seria um momento de aprendizagem mútua.

Um ponto negativo do PNLD é que por ser nacional normalmente suas referências e análises enfatizam mais as características, tendências e visões dos centros econômicos mais desenvolvidos, dificultando muitas vezes um trabalho com conteúdo de forma contextualizada. Rocha analisando a ideia de Nacional relacionada à Base Nacional Comum Curricular afirma que

Em outras palavras, a metonímia entre o "nacional" e o "comum" orienta a reivindicação por uma seleção curricular inquestionável. Contudo, o drama é que o nacional do projeto curricular envolve uma seleção particular que encarna uma totalidade imaginada. Como Moore anunciou na citação, alguns lugares (particulares) projetam práticas da nacionalidade (ROCHA, 2017, p. 266).

Como proposta para superar essa dificuldade seria interessante que além do livro didático do PNLD os professores tivessem acesso a materiais que tratam da localidade onde a escola está inserida, esses materiais muitas vezes são produzidos por meio de pesquisa nas universidades, mas não são utilizados como material didático, são vistos como produto de pesquisa, mas possuem um grande potencial para ser utilizado na escola e contribuírem no processo de contextualização do conteúdo nas aulas de geografia.

O envolvimento de professores da educação básica e professores pesquisadores do ensino superior é um importante passo para a melhoria do processo ensino aprendizagem. Em um artigo onde analisa o uso de trabalhos científicos na educação básica Manoel e Azevedo afirmam que:

Sendo assim, o que fica deste trabalho é a prerrogativa de que é possível se trabalhar, em especial, Trabalhos de Conclusão de Curso de alunos de graduação, como importantes ferramentas metodológicas na instrução à geografia (e outras disciplinas) no processo de ensino e aprendizagem de alunos a partir do nono ano do ensino fundamental - embora saibamos que existam obras que indiretamente possam favorecer também alunos de outras séries. Entretanto, para que sejam utilizadas, é necessário que haja uma "via de mão dupla", onde, por um lado, professores se pré-disponham a buscar tais conhecimentos, e por outro, autores continuem a acreditar e divulgar mais veemente seus trabalhos como fontes de conhecimentos. De forma a propiciar que um vá ao encontro do outro (MANOEL; AZEVEDO, 2017, p. 136).

Além de trabalhos de conclusão de curso outras pesquisas podem contribuir com o processo ensino aprendizagem, como relatórios de pesquisa, relatórios de projetos de extensão e relatórios de análise ambiental. Neste artigo propomos o uso das informações de um relatório final do "Diagnóstico geoambiental da APA da bacia hidrográfica do Rio Machado-MG" para aproximar os alunos do conteúdo da geografia por meio da realidade. 
Para avançarmos a análise é importante entendermos o que é APA. De acordo com a lei $\mathrm{n}^{\mathrm{o}} 13.373$ de 30.11.1999:

Art. $1^{\circ}$ Ficam declarados Área de Proteção Ambiental da Bacia Hidrográfica do Rio do Machado - APA do Rio do Machado - os terrenos que integram a bacia hidrográfica desse rio, nos Municípios de Espírito Santo do Dourado, Congonhal, Ipuiúna, São João da Mata, Poço Fundo, Carvalhópolis, Campestre, Machado, Alfenas, Paraguaçu e Fama.

$\S 1^{\circ} \mathrm{A}$ área de que trata o caput deste artigo, medindo $1.016 \mathrm{~km}^{2}$ (mil e dezesseis quilômetros quadrados), tem seus limites definidos pelo perímetro da bacia hidrográfica do rio do Machado, com 211,8km (duzentos e onze quilômetros e oito hectômetros) de extensão.

É uma área de preservação ambiental que abrange vários municípios, desta forma ao estudar a APA é possível abordar diversos conteúdos de geografia, não se limitando à questão ambiental, como normalmente é feito. O diagnóstico ambiental é resultado das pesquisas de diversos fenômenos naturais e sociais e isso amplia a possibilidade de estudos na geografia escolar.

Existe uma carência de material produzido ou/e organizado sobre essa região que seja acessível à educação básica. A Universidade Federal de Alfenas realiza por meio de projeto de pesquisas e iniciação científica muitas pesquisas que produzem e organizam dados dessa região, no entanto, são pesquisas pontuais e que tratam temas específicos. No caso do relatório do “Diagnóstico geoambiental da APA da bacia hidrográfica do Rio Machado-MG” o produto final traz informações produzidas por diversas áreas da geografia e da biologia, ou seja, os dados estão organizados em um único relatório, o que facilita o acesso.

Esse diagnóstico foi realizado por uma equipe de docentes do Instituto de Ciências da Natureza da Universidade Federal de Alfenas e apresenta dados e análise relacionados aos elementos geográficos e biológicos.

Tendo como base as decisões tomadas na reunião pública, que foram as balizas para as reuniões técnicas posteriores, se estabeleceu uma parceria entre IEF - Machado, UNIFAL-MG e a ARPA Rio Grande - Agência Regional de Proteção Ambiental da Bacia do Rio Grande, sendo realizada entre os meses de maio de 2017 e abril de 2019, objetivando elaborar Relatório Final - Vol. 1 - Diagnóstico e Zoneamento Geoambiental da APA da BHRM. UNIFAL-MG - ARPA Rio Grande - FACEPE - IEF Sul de Minas o diagnóstico geoambiental da APA da Bacia Hidrográfica do Rio Machado, tendo como base a análise integrada de estudos temáticos sobre hidrografia, aspectos climáticos, geologia e solos, geomorfologia e processos erosivos, uso e ocupação da terra e cobertura vegetal, análise demográfica e socioeconômica e levantamento da fauna e flora, nos limites da APA-BHRM. Além dos documentos citados, produziu-se um material didático voltado para professores utilizarem o contexto ambiental da região para o ensino de Geografia e Ciências na educação básica.

As análises mencionadas acima, resultaram na proposição de um zoneamento geoambiental, que juntamente com os estudos temáticos realizados, visam subsidiar estudos subsequentes e auxiliar nas discussões e tomada de decisões sobre a gestão ambiental sustentável no âmbito do conselho APA-BHRM e das demais entidades que atuam na unidade. Além disso, espera-se que este estudo seja uma das bases para a complementação futura dos estudos relacionados ao plano de manejo da APA-BHRM (UNIFAL-MG, 2019, p. 4-5). 
A elaboração das atividades didáticas embasadas no relatório do diagnóstico possibilitou a reflexão que será apresentada neste artigo. Ter contato com esse material e pensar nas possibilidades de metodologia de ensino de geografia foi um momento de muito crescimento, de aproximação de pesquisadores de diversas áreas e de pensar em estratégias que possam aproximar o conhecimento científico da educação básica por meio da didática.

Para ser o norteador das atividades realizadas com base no diagnóstico, foi escolhida a linguagem cartográfica por ser essencial para o ensino de geografia, pois trabalha com a representação do espaço, e também para contribuir com grande parte dos professores de geografia que encontram dificuldades em trabalhar com essa linguagem em sala de aula. De acordo com Duarte (2017, p. 34)

Isto posto advogamos a centralidade do pensamento ou raciocínio espacial se quisermos desenvolver em nossos alunos um modo de pensamento eminentemente geográfico. Para atingir esse fim, o domínio e a aplicação da linguagem cartográfica, encarada como meio para a compreensão de fenômenos espaciais, é parte insubstituível desse processo ensinoaprendizagem.

Para elaborar o material didático sobre o relatório do diagnóstico, foram analisados todos os mapas, gráficos e tabelas produzidos pelas diversas áreas a fim de articular esses dados. É importante colocar que o diagnóstico foi realizado de forma fragmentada, cada área específica elaborou o seu e depois o coordenador do projeto organizou o material. A proposta é avançar nos princípios do raciocínio geográfico presentes na Base Nacional Comum Curricular.

Analogia: Um fenômeno geográfico sempre é comparável a outros. A identificação das semelhanças entre fenômenos geográficos é o início da compreensão da unidade terrestre. Conexão: Um fenômeno geográfico nunca acontece isoladamente, mas sempre em interação com outros fenômenos próximos ou distantes.

Diferenciação: É a variação dos fenômenos de interesse da geografia pela superfície terrestre (por exemplo, o clima), resultando na diferença entre áreas.

Distribuição: Exprime como os objetos se repartem pelo espaço.

Extensão: Espaço finito e contínuo delimitado pela ocorrência do fenômeno geográfico. Localização: Posição particular de um objeto na superfície terrestre. A localização pode ser absoluta (definida por um sistema de coordenadas geográficas) ou relativa (expressa por meio de relações espaciais topológicas ou por interações espaciais).

Ordem: Ordem ou arranjo espacial é o princípio geográfico de maior complexidade. Refere-se ao modo de estruturação do espaço de acordo com as regras da própria sociedade que o produziu (BRASIL, 2017, p. 360).

Esses princípios deveriam ser elementos óbvios na geografia e na geografia escolar, mas é muito comum encontrarmos pesquisas que não tratam a espacialidade e muitas aulas na geografia escolar que abordam o conteúdo sem tratar a dimensão espacial.

Para Simielli existem etapas para trabalhar a cartografia na educação básica: 


\begin{abstract}
Mas para trabalhar com cartografia na educação básica, é necessário se atentar para as possibilidades de acordo com cada nível de ensino. Considerando-se o fato de que o ideal é trabalhar com diferentes mapas para diferentes usuários, principalmente nas várias faixas etárias, proponho para o ensino fundamental, com alunos de $1^{\mathrm{a}}$ a $4^{\mathrm{a}}$ série, trabalhar basicamente com a alfabetização cartográfica, pois este é o momento em que o aluno tem que iniciar-se nos elementos da representação gráfica para que possa posteriormente trabalhar a representação cartográfica (SIMIELLI, 1999, p. 95).
\end{abstract}

De acordo com a autora nos anos iniciais do ensino fundamental os professores são responsáveis por levar os alunos à alfabetização cartográfica. Essa etapa pode ser desenvolvida com uso de desenhos, imagens, maquetes, croquis, mapas mentais, mapas, imagens de satélites etc. Essa etapa é essencial, pois é dela que dependerá a relação dos alunos com as representações cartográficas nos anos posteriores, pois é nesse momento que eles desenvolvem as noções de visão oblíqua e visão vertical, imagem tridimensional, imagem bidimensional, alfabeto cartográfico (ponto, linha e área), construção da noção de legenda, proporção e escala, lateralidade/referência e orientação.

Nos anos finais do ensino fundamental e do ensino médio de acordo com Simielli (1999) os alunos devem ser capazes de realizar a localização e análise em um mapa, correlacionar duas, três ou mais ocorrências e depois avançar para a realização da síntese dessa análise.

Dentro desse contexto da importância da cartografia escolar no ensino de geografia, optou-se neste artigo por propor a reflexão sobre uma possibilidade de metodologia de ensino de geografia que considere a realidade do aluno para fins de contextualização e que as atividades e construção do conhecimento tenham base na representação cartográfica.

\title{
3. ANÁLISE DA SEQUÊNCIA DIDÁTICA I. TRABALHAR ESCALA GEOGRÁFICA, LIMITES E BACIAS HIDROGRÁFICAS.
}

Escala geográfica é um conteúdo que perpassa todo conteúdo de geografia e ao mesmo tempo é uma questão muito abstrata para se trabalhar com os alunos. A escala geográfica trata de um recorte espacial para definir uma área, uma extensão, e, dependendo do objetivo, podemos utilizar as seguintes escalas geográficas ou recorte espacial: local, regional, nacional, mundial/global.

Os livros didáticos normalmente tratam esse conteúdo nas séries iniciais do ensino fundamental ou no sexto ano do ensino fundamental II, pois os alunos precisam desenvolver esse raciocínio para que a geografia consiga avançar na educação básica. $\mathrm{O}$ aluno precisa desenvolver o raciocínio que seu município compõe um estado que compõe uma região, que compõe um país, que compõe um continente e que os continentes formam o mundo.

Para trabalhar esse conteúdo propomos iniciar a sequência didática com a música "Ora Bolas", cantada pelo grupo Palavra Cantada, composição de Paulo Tatit e Edith Derdyk. A letra dessa 
música permite que os alunos entendam a relação entre os lugares e contribui na construção da escala geográfica.

Ora bolas (Palavra Cantada)

Oi oi oi,

Olha aquela bola

A bola pula bem no pé, no pé do menino

Quem é esse menino?

Esse menino é meu vizinho!

Onde ele mora?

Mora lá naquela casa!

Onde está a casa?

A casa tá na rua!

Onde está a rua?

Tá dentro da cidade.

Onde está a cidade?

Tá do lado da floresta!

Onde está a floresta?

A floresta é no Brasil!

Onde está o Brasil?

Tá na América do Sul, no continente americano,

Cercado de oceanos e das terras mais distantes

De todo o planeta.

E como é o planeta?

O planeta é uma bola,

Que rebola lá no céu.

Oi,oi,oi.

Olha aquela bola

A bola pula bem no pé, no pé do menino (TATIT, s.d.)

(Disponível em: https://www.youtube.com/watch?v=CRzN1GYlYWM)

A proposta é primeiro trabalhar a música e deixar os alunos pensarem sobre ela, criar no imaginário o espaço representado pela música. Depois desse momento é interessante, se possível, trabalhar com o vídeo que ilustra cada passo da música de forma que mostra que os recortes espaciais estão interligados partindo do local e intercalando ao global, quebrando assim a ideia de círculo concêntrico ainda presentes no ensino de geografia. Para Callai (2005, p. 230)

São os Círculos Concêntricos, que se sucedem numa seqüência linear, do mais simples e próximo ao mais distante. Na realidade, esse procedimento constitui mais um problema do que uma solução, pois o mundo é extremamente complexo e, em sua dinamicidade, não acolhe os sujeitos em círculos que se ampliam sucessivamente do mais próximo para o mais distante.

A letra da música e seu ritmo, bem como as imagens do vídeo, partem do mais próximo ao mais distante, mas não de uma maneira isolada, mas sim mostrando que esse conjunto se completa, estão interligados. Ainda dentro dessa discussão Callai (2005, p. 230) afirma que:

O que se está questionando é uma postura teórica que dá a referência, a forma de encaminhamento, postura que considera um espaço fragmentado e circular, o qual se amplia sucessivamente. Partindo do "eu”, da família, cria-se uma proposição antropocêntrica - ou 
melhor, egocêntrica - ao redor do "eu". O problema não é partir do "eu", mas sim fragmentar os espaços que se sucedem e que passam a ser considerados isoladamente, como se tudo se explicasse naquele e por aquele lugar mesmo. A dinâmica do mundo é dada por outros fatores. E o desafio é compreender o "eu" no mundo, considerando a sua complexidade atual.

E a proposta de usar o relatório do Diagnóstico da APA do Rio Machado é partir de uma contextualização e avançar relacionando o contexto local dos alunos, ou seu espaço vivido, com as relações globais e nacionais. Tornar a geografia mais significativa para os alunos tendo como base dados da sua realidade ou da sua região, mas sempre vinculada às relações globais.

A música e o vídeo são linguagem presentes na vida cotidiana dos alunos que desde muito cedo têm contato com essas linguagens com objetivo de entretenimento e/ou de aprendizagem, e elas contribuem para que o professor de geografia trabalhe com um pouco de lúdico nas aulas, por isso é importante utilizá-las nas aulas de geografia.

Após o trabalho com a música e com o vídeo pode ser inserido um trabalho com a linguagem cartográfica, por meio de um mapa, como a proposta é utilizar o material elaborado por meio do relatório do Diagnóstico da APA do Rio Machado, optou-se por utilizar o mapa elaborado pela equipe de geoprocessamento (Figura 1).

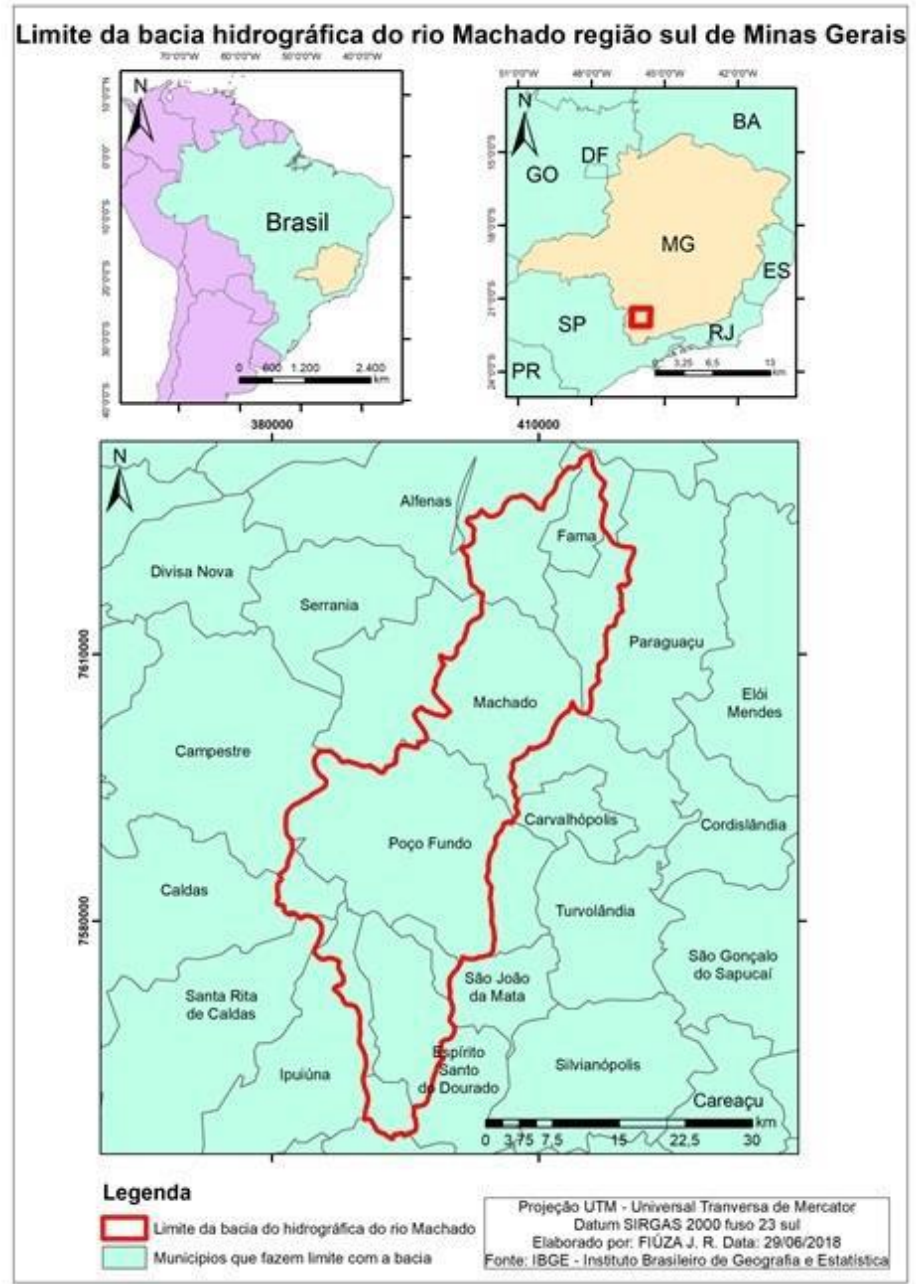

Figura 1 - Localização da área de estudo.

Fonte - UNIFAL-MG, 2019. 
É importante que o professor leve os alunos a analisarem os mapas, sem fazer a leitura do mesmo para os alunos, é importante que os alunos sejam capazes de levantar hipóteses ao analisar os mapas. Após as manifestações dos alunos a mediação deve direcionar ao aluno a lembrar da letra da música e fazer com que ele perceba que Minas Gerais está dentro do Brasil e quais países fazem fronteira com o Brasil, chamar atenção para os estados que fazem limite com Minas Gerais e quais os municípios fazem limite com o município onde a escola se localiza, ou onde o aluno reside.

Para as séries finais do ensino fundamental I e Ensino Médio é possível ampliar esta temática para aprofundar a discussão de limites e fronteiras. No senso comum limites e fronteiras são abordados como sinônimos, mas para a geografia essa é uma questão muito importante que envolve aspectos políticos, econômicos e sociais.

Segundo Martin (1997, p. 47), "hoje o limite é reconhecido como linha, e não pode, portanto, ser habitada, ao contrário da fronteira, que [...] constitui uma zona, muitas vezes bastante povoada onde os habitantes de Estados vizinhos podem desenvolver intenso intercâmbio, em particular sob a forma de contrabando". Nesse contexto, o limite político territorial cria um lugar de ação social que é instrumentalizado pela atuação do poder, no sentido de que esse poder governa, controla, regula e restringe determinadas ações no espaço delimitado, além de excluir outros poderes não pertencentes a essa lógica de participarem desse circuito, por detrás disso está a ideia de soberania consagrada conjuntamente com a constituição do Estado moderno.

O limite não pode ser visto fora do mapa, sendo uma realidade cartográfica, simbolizada pelos marcos fronteiriços no espaço físico com o intuito de se criar uma linha imaginária, mas com efeitos práticos comprovados (FERRARI, 2014). Segundo Raffestin (1993, p. 169-70), os limites são "portadores de uma informação que consome energia, para ser criado, controlado e mantido, não concernem somente ao invólucro espaço temporal. Eles fazem parte do nosso jogo de reprodução social: produção, troca, consumo". Por outro lado, a fronteira é perceptível quando se pensa em uma zona geográfica, consubstanciada pelas cidades, populações e relações que nela se estabelecem (COSTA, 2017, p. 32).

Mediar a aprendizagem levando o aluno a refletir sobre esses conteúdos partindo de sua realidade e relacionando com as questões nacionais e globais torna a geografia mais significativa e mais prazerosa para o aluno. Para isso é importante que o professor tenha um olhar atento e críticos aos instrumentos de ensino e que explorem todas as possibilidades dos mesmos.

Além dos limites entre países, estados e municípios outro elemento que deve ser trabalhado por meio desta figura é o limite da bacia hidrográfica. No caso da APA do Rio Machado, o limite da mesma é compatível com o limite da bacia hidrográfica, ou seja, um limite natural. Porto e Porto (2008, p.45) definem a bacia hidrográfica como

\footnotetext{
A bacia hidrográfica é uma área de captação natural da água de precipitação que faz convergir o escoamento para um único ponto de saída. A bacia hidrográfica compõe-se de um conjunto de superfícies vertentes e de uma rede de drenagem formada por cursos de água que confluem até resultar em um leito único no seu exutório (Tucci, 1997).
} 
A bacia hidrográfica pode ser então considerada um ente sistêmico. É onde se realizam os balanços de entrada proveniente da chuva e saída de água através do exutório, permitindo que sejam delineadas bacias e sub-bacias, cuja interconexão se dá pelos sistemas hídricos.

Bacia hidrográfica é um conteúdo muito trabalhado na geografia escolar, na Base Nacional Curricular Comum encontramos algumas habilidades entendidas como obrigatória para o ensino fundamental II que tratam desta temática:

(EF06GE04) Descrever o ciclo da água, comparando o escoamento superficial no ambiente urbano e rural, reconhecendo os principais componentes da morfologia das bacias e das redes hidrográficas e a sua localização no modelado da superfície terrestre e da cobertura vegetal.

(EF06GE12) Identificar o consumo dos recursos hídricos e o uso das principais bacias hidrográficas no Brasil e no mundo, enfatizando as transformações nos ambientes urbanos.

(EF08GE15) Analisar a importância dos principais recursos hídricos da América Latina (Aquífero Guarani, Bacias do rio da Prata, do Amazonas e do Orinoco, sistemas de nuvens na Amazônia e nos Andes, entre outros) e discutir os desafios relacionados à gestão e comercialização da água (BRASIL, 2017, p. 385, 385).

Normalmente esses conteúdos constam nos livros didáticos, mas de forma relacionada ao território nacional e não às particularidades de cada lugar. Trabalhar com o relatório de Diagnóstico da APA do Rio Machado permite trabalhar esse conceito de forma mais próxima à realidade do aluno, conseguindo contextualizar de forma mais específica esse conteúdo.

\begin{abstract}
A questão da escala a ser utilizada depende do problema a ser solucionado. Pode ser delimitada a totalidade da bacia do Rio Amazonas, desde suas cabeceiras mais distantes na cordilheira andina até seu exutório do Oceano Atlântico, assim como podem ser delimitadas suas sub-bacias, maiores ou menores, dependendo da necessidade do problema a ser abordado. Diz-se que o tamanho ideal de bacia hidrográfica é aquele que incorpora toda a problemática de interesse. Pode-se ter interesse em uma pequena bacia de $0,5 \mathrm{~km}^{2}$ numa área urbana, como na bacia do Rio São Francisco, com mais de seus $600.000 \mathrm{~km}^{2}$ de área. Esse conceito sistêmico adapta-se muito bem aos sistemas de gestão de recursos hídricos.

Sobre o território definido como bacia hidrográfica é que se desenvolvem as atividades humanas. Todas as áreas urbanas, industriais, agrícolas ou de preservação fazem parte de alguma bacia hidrográfica. Pode-se dizer que, no seu exutório, estarão representados todos os processos que fazem parte do seu sistema. O que ali ocorre é consequência das formas de ocupação do território e da utilização das águas que para ali convergem (PORTO; PORTO, 2008, p. 45).
\end{abstract}

Por meio desse mapa (Figura 2) elaborado pela equipe que analisou os recursos hídricos do Diagnóstico da APA do Rio Machado é possível levar os alunos a aproximarem o conteúdo de sua realidade no processo de construção do conceito geográfico.

O professor deve mediar a aprendizagem para que os alunos explorem o mapa, identifiquem os cursos d'água, a fim de que questionem se esses cursos foram canalizados ou se conseguem ter 
acesso a eles, quais são seus usos no cotidiano etc. Dessa forma o conceito deixa de ser abstrato e passa a fazer parte da realidade do aluno.

Muitas vezes nas aulas de geografia na educação básica, o professor se limita a explicar o que são as bacias hidrográficas e sua composição. Enfatiza as principais bacias hidrográficas do Brasil, eventualmente pede ao aluno para copiar em folha vegetal esse mapa e colar no caderno, sem dar a devida importância para o espaço geográfico ocupado pelo aluno.

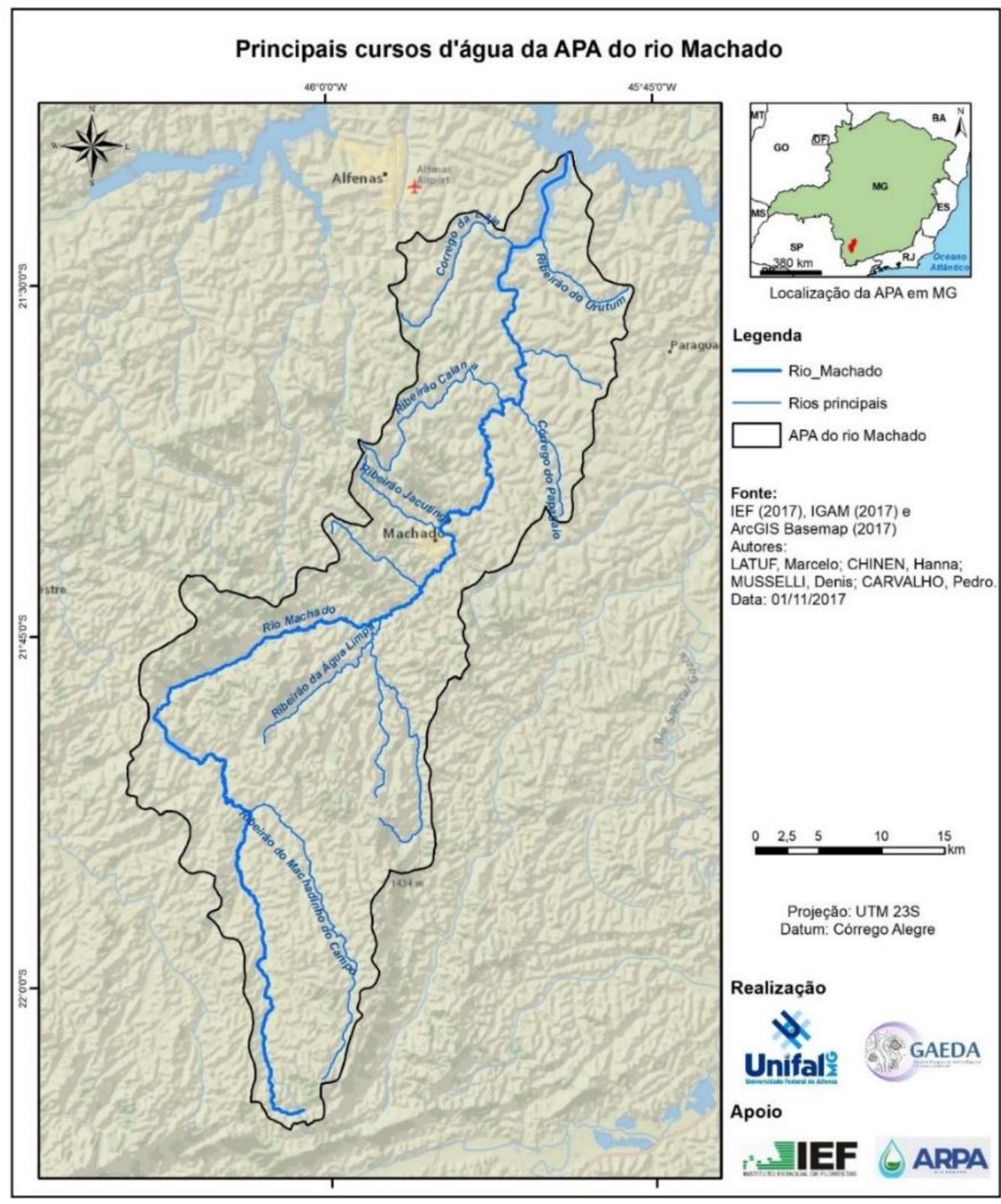

Figura 2 - Principais cursos d'água da APA do Rio Machado.

Fonte - UNIFAL-MG, 2019 
A bacia hidrográfica é um recorte espacial que permite uma análise que relaciona a sociedade à natureza, ou seja, ensinar geografia por meio desse recorte espacial pode ser muito enriquecedor, pois parte da dimensão espacial e insere as dimensões física e humana que compõem a ciência geográfica.

\section{CONSIDERAÇÕES IMPORTANTES}

A geografia escolar é um importante instrumento para entender a realidade, e essa é uma das suas principais funções na educação básica, dessa forma a contextualização do conteúdo é essencial nesse processo, não a contextualização que isola a realidade do aluno, mas a contextualização que leva o aluno a pensar que sua realidade é resultado de um processo global e que existem relações que ocorrem em seu espaço vivido com várias escalas geográficas, não a contextualização que só mostra o que existe, mas um processo que além de mostrar o que existe indica que há possibilidade de mudanças.

Por meio do uso do relatório do Diagnóstico da APA do Rio Machado foi possível comprovar que os conteúdos produzidos na universidade por meio de pesquisas podem ser enriquecedores do processo ensino aprendizagem na educação básica, mas para isso é necessário que esse conhecimento ultrapasse os limites da universidade e alcance as escolas, no caso do material utilizado, ele foi resultado de parceria entre a Associação Regional de Proteção Ambiental da Bacia do Rio Grande (ARPA) e a UNIFAL-MG, movimento que favorece a universidade e a associação, e nessa parceria já estava prevista a elaboração de um material didático. Mas é importante ressaltar que além do material didático são necessários cursos de formação continuada para que os professores se preparem para trabalhar esse material e que possam construir com a universidade metodologias de ensino.

\section{REFERÊNCIAS}

BRASIL. Ministério da Educação. Secretaria da Educação Básica. Base nacional comum curricular. Brasília, DF, 2017. Disponível em: < http://basenacionalcomum.mec.gov.br/\#/site/inicio>. Acesso em: 10 maio 2019.

CALLAI, H. C. Aprendendo a ler o mundo: a geografia nos anos iniciais do ensino fundamental. Caderno Cedes, Campinas, v. 25, n. 66, p. 227-247, 2005.

CAVALCANTI, L. S. A geografia e a realidade escolar contemporânea: avanços, caminhos, alternativas. In: SIMPÓSIO NACIONAL: CURRÍCULO EM MOVIMENTO. 1., 2010, Belo Horizonte. Anais... Belo Horizonte: 2010. p. 1-16. 
. O trabalho do professor de geografia e tensões entre demandas da formação e do cotidiano escolar. In: ASCENÇÃO, V. O. R. (org.). Conhecimentos da geografia: percursos de formação docente e práticas na educação básica. Belo Horizonte: IGC, 2017. p.100-123.

COSTA, M. K. B. Políticas de segurança e defesa da fronteira brasileira no contexto de integração regional: os casos das fronteiras Brasil-Paraguai e Brasil-Uruguai. 2017. $210 f$. Dissertação (Mestrado em Relações Internacionais) — Universidade de Brasília, Brasília, 2017.

DUARTE, R. G. A cartografia escolar e o pensamento (geo)espacial: alicerces da educação geográfica. In: ASCENÇÃO, V. O. R. (org.). Conhecimentos da geografia: percursos de formação docente e práticas na educação básica. Belo Horizonte: IGC, 2017. p. $28-52$.

MANOEL, L.; AZEVEDO, S. C. A utilização de trabalhos de conclusão de curso como ferramenta metodológica e de inclusão no ensino de geografia na educação básica. In: SIMPÓSIO NACIONAL POR UMA ESCOLA INOVADORA E INCLUSIVA: DESAFIOS À EDUCAÇÃO DO SÉCULO XXI. 1., 2017, Poços de Caldas. Anais... Poços de Caldas: UNIFAL, 2017, p. 128-138.

MINAS GERAIS. Lei Estadual no 13.373, de 30 de novembro de 1999. Dispõe sobre a criação da Área de Proteção Ambiental da bacia Hidrográfica do Rio Machado - APA do Rio Machado, e dá outras providências, Belo Horizonte, 30 nov. 1999.

MUNAKATA, K. Livro didático como indício da cultura escolar. Hist. Educ. [online], v. 20, n. 50, p. 119-138, 2016.

PORTO, M. F. A.; PORTO, R. L. L. Gestão de bacias hidrográficas. Estudos Avançados, São Paulo, v. 22, n. 63, p. 43-63, 2008.

ROCHA, A. A. O "Nacional" nos documentos curriculares: uma exploração empírica. In: ASCENÇÃO, V. O. R. (org.). Conhecimentos da geografia: percursos de formação docente e práticas na educação básica. Belo Horizonte: IGC, 2017. p. 261-287.

SIMIELLI, M. E. R. Cartografia no ensino fundamental e médio. In: CARLOS, A. F. A. (org.). A geografia na sala de aula. São Paulo: Contexto, 1999. - (Repensando o ensino). p. 92-108

TATIT, P.; DERDYK, E. Ora bolas. 2017. Disponível em: <http://palavracantada.com.br/musica lora-bolas/>. Acesso em: 12 maio 2019.

UNIFAL-MG. Relatório Final. Diagnóstico e Zoneamento Geoambiental da APA da Bacia Hidrográfica do Rio Machado-MG. Alfenas-MG: s.n., 2019. 2 v.

VITIELLO, M. A. A geografia censurada: cerceamento à produção e a distribuição de livros didáticos. 1. ed. Curitiba: Appris, 2018. 227p.

ZACHEU, A. A. P.; CASTRO, L. L. O. Dos tempos imperiais ao PNLD: a problemática do livro didático no Brasil. In: JORNADA DO NÚCLEO DE ENSINO DE MARÍLIA. 14., 2015, Marília. Anais... Marília: UNESP, 2015. p. 1-12. 